Check for updates

Cite this: RSC Adv., 2017, 7, 49024

Received 21st August 2017

Accepted 11th October 2017

DOI: $10.1039 / c 7 r a 09234 b$

rsc.li/rsc-advances

\section{Heterogeneous Fenton-like catalysis of Fe-MOF derived magnetic carbon nanocomposites for degradation of 4-nitrophenol $\uparrow$}

\author{
Dezhi Chen, (D) *a Shasha Chen, ${ }^{a}$ Yijie Jiang, ${ }^{a}$ Shasha Xie, ${ }^{a}$ Hongying Quan, ${ }^{\text {b }} \mathrm{Li} \mathrm{Hua}{ }^{a}$ \\ Xubiao Luo iD *a and Lin Guo ${ }^{\text {ac }}$
}

\begin{abstract}
Magnetic carbon nanocomposites $\left(\mathrm{Fe}-\mathrm{C}_{x}\right)$ as heterogeneous Fenton-like catalysts were synthesized by the pyrolysis of iron based metal-organic frameworks (Fe-MOF), and the degradation removal of 4-nitrophenol (4-NP) in aqueous solution was used to evaluate the catalytic activity of $\mathrm{Fe}-\mathrm{C}_{x}$. The results showed that 4-NP could be effectively degraded by $\mathrm{Fe}-\mathrm{C}_{x}$ in the presence of hydrogen peroxide. Pyrolysis temperature significantly affected the component, structures and performances of the catalysts, and the as-prepared $\mathrm{Fe}-\mathrm{C}_{500}$ exhibited the best catalytic performance. Furthermore, the effects of several reaction conditions, such as catalyst loading, $\mathrm{H}_{2} \mathrm{O}_{2}$ dosage, reaction temperature, and initial $\mathrm{pH}$, on the catalytic degradation of 4-NP were extensively analyzed for the practical applications of $\mathrm{Fe}-\mathrm{C}_{500}$. At an initial circumneutral $\mathrm{pH}$ of $6.21,89.0 \%$ of $0.36 \mathrm{mM} 250 \mathrm{~mL}$ of $4-\mathrm{NP}$ solution could be degradated after $75 \mathrm{~min}$ by the heterogeneous Fenton-like oxidation on the $0.08 \mathrm{~g} \mathrm{~L}^{-1}$ of $\mathrm{Fe}-\mathrm{C}_{500}$ in the presence of $7.8 \mathrm{mM} \mathrm{H}_{2} \mathrm{O}_{2}$. The results of activation energy and the reaction kinetics showed $\mathrm{Fe}-\mathrm{C}_{500}$ possessed a high catalytic activity in the heterogeneous Fenton reaction of 4-NP. Moreover, the prepared Fe- $\mathrm{C}_{500}$ could be reused by an external magnet, and still retained good catalytic activity with $52.4 \%$ degradation of 4-NP at the fourth cycle.
\end{abstract}

\section{Introduction}

With the wide use of pesticides, drugs, dyes, and other organic matter, increasingly detrimental pollutants are discharging into environment, which will cause great damage to the health of humans and other creatures. ${ }^{1,2}$ Therefore, it is significant to take effective measures to dispose of these contaminants. Various methods, including adsorption, ${ }^{3}$ flocculation, ${ }^{4}$ membrane filtration, ${ }^{5}$ microorganism degradation, ${ }^{6}$ have been investigated and developed to remove organic pollutants from effluent. However, some of these processes suffer from drawbacks such as partial degradation of the effluent, toxic byproducts and excessive sludge production, energy consumption, and secondary phase generation that imposes extra cost in the process. $^{7-9}$ Therefore, it is necessary to improve the

${ }^{a}$ Key Laboratory of Jiangxi Province for Persistent Pollutants Control and Resources Recycle, School of Environmental and Chemical Engineering, Nanchang Hangkong University, No. 696, Fenghe South Avenue, Nanchang, 330063, China. E-mail: chendz@nchu.edu.cn; luoxubiao@nchu.edu.cn

${ }^{b}$ School of Materials Science and Engineering, Nanchang Hangkong University, No. 696, Fenghe South Avenue, Nanchang 330063, China

${ }^{c}$ Key Laboratory of Bio-Inspired Smart Interfacial Science and Technology of Ministry of Education, School of Chemistry and Environment, Beihang University, No. 37 Xueyuan Road, Haidian District, Beijing 100191, China

$\dagger$ Electronic supplementary information (ESI) available. See DOI: 10.1039/c7ra09234b treatment efficiency of conventional wastewater treatment methods. Advanced oxidation processes (AOPs), such as Fenton oxidation consisting of catalyst $\left(\mathrm{Fe}^{2+} / \mathrm{Fe}^{3+}\right)$ and hydrogen peroxide $\left(\mathrm{H}_{2} \mathrm{O}_{2}\right)$, have been found to be effective at degrading recalcitrant and chemically complicated organics contaminants. ${ }^{10,11}$ However, there are still certain limitations regarding the application of Fenton oxidation processes. The homogeneous type operates in a narrow range of $\mathrm{pH}(2-4)$, and large quantities of acid are required and a neutralization step is required afterward. ${ }^{11-15}$ Furthermore, the stoichiometric amounts of iron are required, and very hard to remove after the reaction. Therefore, this process can also generate secondary pollution (e.g. acid or metal ions) as well as metal hydroxide sludge. To overcome these problems, heterogeneous Fentonlike catalysts based on iron-containing solids have been intensively investigated. ${ }^{13,14,16-21}$ Among iron-containing solids, magnetic recoverable nanoparticles $\left(\mathrm{Fe}_{3} \mathrm{O}_{4}, \gamma-\mathrm{Fe}_{2} \mathrm{O}_{3}\right.$, and $\left.\mathrm{Fe}^{0}\right)$ show effective heterogeneous Fenton catalyst because of their highly acceptable reusability and stability, low toxicity, and easy separation. ${ }^{22-24}$ However, these magnetic iron-based nanoparticles have a strong tendency to agglomerate, resulting in the reduce of their catalytic activity. ${ }^{25,26}$ To circumvent the obstacle, carbonaceous materials with high conduct electricity, specific surface area and porosity, have been widely chosen as matrices for loading of magnetic nanoparticles, which not only can enhance electron transfer and increase the active sites for the 
degradation of pollutants in water but also facilitate the separation of catalyst from water system. ${ }^{\mathbf{1 4 , 2 5 , 2 7 - 2 9}}$

Recently, the pyrolysis of metal-organic frameworks (MOFs) has been considered an effective and simple way to construct magnetic recoverable iron-containing nanoparticles/porous carbon composites using in Fenton-like reaction for the degradation of organic pollution in aqueous system. ${ }^{17,30-32}$ For example, MIL-53(Fe)-derived magnetic $\gamma-\mathrm{Fe}_{2} \mathrm{O}_{3} / \mathrm{C}$ showed high catalytic activity for the degradation of malachite green under sunlight in the presence of $\mathrm{H}_{2} \mathrm{O}_{2} \cdot{ }^{30}$ Magnetic iron/carbon nanorods derived from MIL-88A could activate peroxide for the decolorization of rhodamine $\mathrm{B}$ in water. ${ }^{17}$ During the pyrolysis process, these Fe-MOFs were gradually decomposed to magnetic iron-containing nanoparticles/porous carbon composites with the increase of temperature under inert atmosphere. Therefore, the pyrolysis temperature is key factor for the morphology, structure, and activity of product. However, until now there has been a lack of such information to the best of our knowledge. Herein, porous magnetic carbon composites with iron-based nanoparticles were prepared by the thermal decomposition of Fe-MOF at different temperature in $\mathrm{N}_{2}$ atmosphere. The catalytic activity of obtained magnetic products for the heterogeneous Fenton-like degradation of 4-nitrophenol (4-NP) in aqueous solution was studied in detail.

\section{Experimental section}

\subsection{Materials}

Iron(III) chloride hexahydrate $\left(\mathrm{FeCI}_{3} \cdot 6 \mathrm{H}_{2} \mathrm{O}\right), p$-phthalic acid (PTA), $N, N$-dimethylformamide (DMF), hydrogen peroxide $\left(\mathrm{H}_{2} \mathrm{O}_{2}\right)$, ethanol, $n$-butyl alcohol was analytical reagent grade and used directly without further purification.

\subsection{Preparation of Fe-MOF and magnetic carbon nanocomposites}

Fe-MOF was synthesized by the previous report with some modifications. ${ }^{33}$ In a typical preparation, $15.5 \mathrm{~g} \mathrm{FeCI} 3 \cdot 6 \mathrm{H}_{2} \mathrm{O}$ and $10.6 \mathrm{~g}$ PTA was mixed in $640 \mathrm{~mL}$ DMF solution by magnetic stirring until complete dissolution, and then the above mixture was transferred into a three-neck round bottom flask connected to condenser and heated at $100{ }^{\circ} \mathrm{C}$ for 12 hours in an oil bath with magnetic stirring. After naturally cooled to room temperature, the supernatant was centrifuged to obtain orange-yellow product. The product was washed using ethanol for several times and dried in vacuum at $80{ }^{\circ} \mathrm{C}$ for 24 hours. Finally, the solid Fe-MOF powder was annealed in a tube furnace at different temperature $\left(400{ }^{\circ} \mathrm{C}, 450{ }^{\circ} \mathrm{C}, 500{ }^{\circ} \mathrm{C}, 550{ }^{\circ} \mathrm{C}, 600{ }^{\circ} \mathrm{C}\right)$ (ramp rate, $1^{\circ} \mathrm{C} \min ^{-1}$ ) for 1 hour in a $\mathrm{N}_{2}$ atmosphere to prepare the magnetic carbon nanocomposites. The obtained magnetic carbon materials were labelled as $\mathrm{Fe}-\mathrm{C}_{x}$, where $x$ denoted the heating temperature.

\subsection{Characterization}

Thermogravimetric analysis (TGA) was used to measure the thermal stability of the Fe-MOF. X-ray diffractometer (XRD, D8 Advanced, Bruker, at $40 \mathrm{kV}$ and $40 \mathrm{~mA}, \mathrm{Cu} \mathrm{K} \alpha$ radiation, $\lambda=1.5406 \AA$ ) and scanning electron microscope (FEI Quanta 450 ) with an acceleration voltage of $10 \mathrm{kV}$ was used to characterize the phase and morphology of Fe-MOF and magnetic $\mathrm{Fe}-\mathrm{C}_{x}$ nanocomposites, respectively. X-ray photoelectron spectroscopy (XPS, Thermo Scientific ESCALAB 250, A1 K $\alpha$ radiation) was used to analyse the elemental composition and corresponding chemical state in the surface of Fe-MOF and magnetic $\mathrm{Fe}-\mathrm{C}_{x}$ nanocomposites. TriStar II 3020 surface area and pore size analyser (Micromeritics) was used to obtain the nitrogen adsorption-desorption isotherms of magnetic $\mathrm{Fe}-\mathrm{C}_{x}$ nanocomposites. The specific surface area, total pore volume and pore-size distribution of the $\mathrm{Fe}-\mathrm{C}_{x}$ nanocomposites was determined by the Brunauer-Emmett-Teller (BET) and Barrett-Joyner-Halenda (BJH) method, respectively. Magnetic properties were tested using a physical properties measurement system (PPMS-DynaCool, Quantum Design, USA) equipped with a 9T vibrating sample magnetometer (VSM).

\subsection{Heterogeneous Fenton-like catalytic activity measurement}

The target contaminate was 4-nitrophenol (4-NP). In a typical experiment, $250 \mathrm{~mL}$ of $4-\mathrm{NP}$ aqueous solution $(0.36 \mathrm{mM})$ and a certain amount of catalysts were mixed and magnetically stirred for $30 \mathrm{~min}$ to ensure the establishment of an adsorption/ desorption equilibrium. Then, a certain amount of $\mathrm{H}_{2} \mathrm{O}_{2}$ aqueous solution was added into the reactor. The heterogeneous Fenton-like degradation was carried on during $75 \mathrm{~min}$ as soon as the $\mathrm{H}_{2} \mathrm{O}_{2}$ aqueous solution was added. At the intervals of given time, $2 \mathrm{~mL}$ of the suspension was collected and the degradation reaction was stopped by adding $n$-butyl alcohol. Then, the suspension was filtered using $0.22 \mu \mathrm{m}$ membrane filter to remove the catalysts and the 4-NP concentration was determined by using a UV spectrophotometer. The reusability of the catalyst was evaluated by washing and drying the catalyst in air oven at $120^{\circ} \mathrm{C}$ for overnight and using it for dye degradation under similar experimental conditions. Each experiment was repeated three times.

\section{Results and discussion}

\subsection{Thermal stability of Fe-MOF}

To prepare magnetic $\mathrm{Fe}-\mathrm{C}_{x}$ nanocomposites, the thermal stability of Fe-MOF is important and characterized by TGA in $\mathrm{N}_{2}$ atmosphere at a heating rate of $1{ }^{\circ} \mathrm{C} \mathrm{min}^{-1}$. The obtained TGA curve, shown in Fig. 1, suggests that it has three steps for mass loss of as-prepared Fe-MOF sample with increasing temperature. The first mass loss is about $3 \%$ below $200{ }^{\circ} \mathrm{C}$, which can be attributed to the removal of adsorbed water and DMF. The second mass loss between 200 and $365{ }^{\circ} \mathrm{C}$ is $23.2 \%$ mainly resulting from the decomposition of oxygen-containing groups in the organic ligands of PTA and DMF of Fe-MOF, and a narrow endothermic peak at $365{ }^{\circ} \mathrm{C}$ can be found during the second weight loss process. With the increasing temperature, the mass loss of step 3 from $365^{\circ} \mathrm{C}$ to $586{ }^{\circ} \mathrm{C}$ may be attributed to the loss of chlorine, the decomposition of aromatic rings, the conformation of iron oxides and the conversion between iron oxides. ${ }^{34}$ 


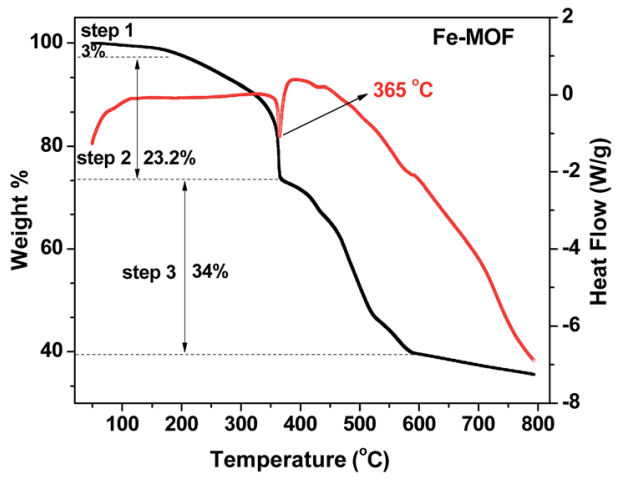

Fig. 1 TGA curves of the as-prepared Fe-MOF from $50{ }^{\circ} \mathrm{C}$ to $800^{\circ} \mathrm{C}$.

The conversion could be attributed to the incomplete calcined products as evidenced by thermal stability. After $600{ }^{\circ} \mathrm{C}$, the mass of material was relatively stable. Therefore, the pyrolysis products of Fe-MOF sample from 400 to $600{ }^{\circ} \mathrm{C}$ were used as catalyst for the Fenton-like degradation of organic pollution.

The phase of the as-prepared samples under different pyrolysis temperature was demonstrated by powder X-ray diffraction, and depicted in Fig. 2a. From Fig. 2a, we can see six well-defined diffraction peaks at 9.4, 12.6, 16.6, 18.8, 21.9 and $28.4^{\circ}$, which is in accordance with that of MIL-101(Fe) $\left(\mathrm{Fe}_{3}(\mathrm{O}) \mathrm{Cl}\left[\mathrm{C}_{6} \mathrm{H}_{4}\left(\mathrm{CO}_{2}\right)_{2}\right]_{3}\left(\mathrm{C}_{3} \mathrm{H}_{7} \mathrm{NO}\right)\right)$ in previous reported
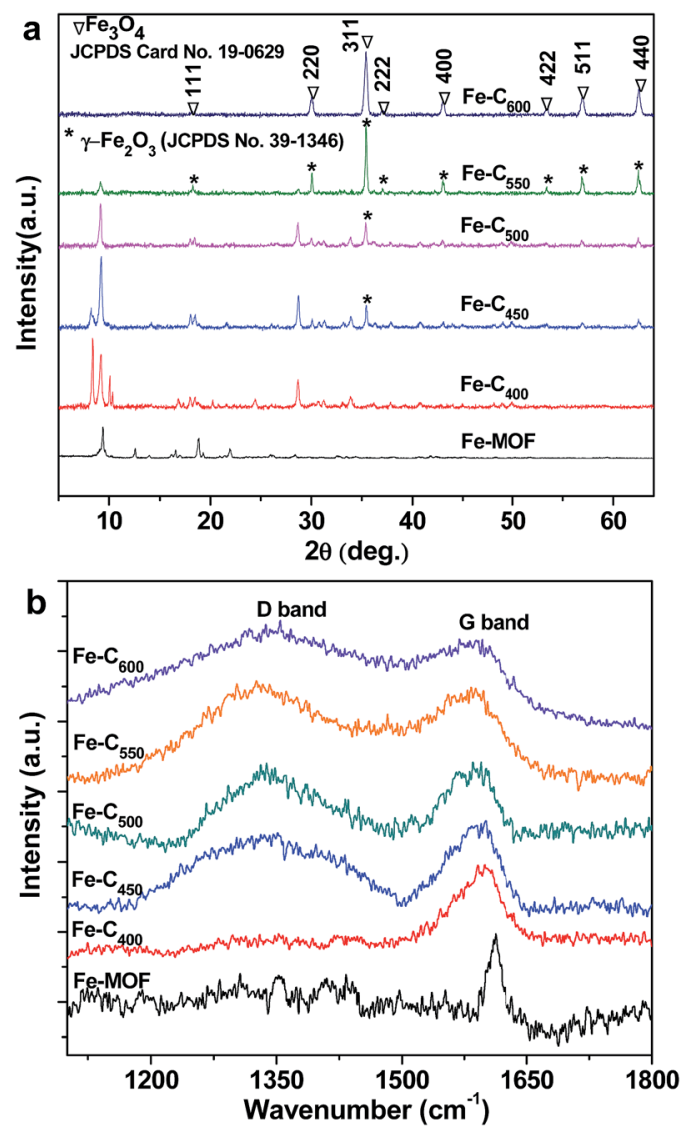

Fig. 2 (a) Powder XRD patterns and (b) Raman spectra of Fe-MOF and $\mathrm{Fe}-\mathrm{C}_{x}$. literatures. ${ }^{35,36}$ After heat treatment at $400{ }^{\circ} \mathrm{C}$, the as-obtained $\mathrm{Fe}-\mathrm{C}_{400}$ exhibits that the main diffraction peaks appear in three areas between 8 to $10^{\circ}, 15$ to $20^{\circ}$ and 28 to $35^{\circ}$, which is different with that of the bare Fe-MOF. It indicates that the phase of Fe-MOF was completely changed at $400{ }^{\circ} \mathrm{C}$ because of loss of part of oxygen-containing groups. However, no any diffraction peaks belong to iron oxides, which suggests that the temperature of $400{ }^{\circ} \mathrm{C}$ was not enough for the decomposition of the Fe-MOF to iron oxide and carbon, and the $\mathrm{Fe}^{-\mathrm{C}_{400}}$ was intermediate product between the Fe-MOF and iron oxide/ carbon composites. The typical pattern of $\mathrm{Fe}-\mathrm{C}_{400}$ implies that the $\mathrm{Fe}-\mathrm{C}_{400}$ may still be metal-organic complexes. When the temperature was increased to $450{ }^{\circ} \mathrm{C}$, part of peaks between 8 and $10^{\circ}$ disappear, and new peak raises at $2 \theta=35.5^{\circ}$, which may be assigned to (311) planes of $\gamma-\mathrm{Fe}_{2} \mathrm{O}_{3}$ (JCPDS no. 39-1346). With the temperature to $500{ }^{\circ} \mathrm{C}$, new diffraction peaks at about 18.6, 30.3, 35.5, 37.3, 43.3, 53.7, 57.2 and $62.7^{\circ}$ appear and old diffraction peaks such as $8.2,9.2,10,28$ and $35^{\circ}$ fall off. The intensity of these new diffraction peaks gradually increases and those pristine diffraction peaks gradually disappear until the temperature was increased to $600{ }^{\circ} \mathrm{C}$. The mainly diffraction peaks of $\mathrm{Fe}-\mathrm{C}_{600}$, present in Fig. $2 \mathrm{a}$ at $2 \theta$ values about 18.6, 30.3, $35.4,37.3,43.31,53.7,57.2$ and $62.7^{\circ}$ correspond to (111), (220), (311), (222), (400), (422), (511) and (440), respectively, which are readily indexed to a pure phase of $\mathrm{Fe}_{3} \mathrm{O}_{4}$ (JCPDS card no. 190629). Meanwhile, it indicates that the $\mathrm{Fe}-\mathrm{C}_{x}(450,500,550)$ are multicomponent.

Fig. $2 \mathrm{~b}$ shows the Raman spectra of $\mathrm{Fe}-\mathrm{MOF}$ and $\mathrm{Fe}-\mathrm{C}_{x}$. For the Fe-MOF, an apparent characteristic peak at $1612 \mathrm{~cm}^{-1}$, as presented in Fig. 2b, is assigned to the vibration of $\mathrm{C}-\mathrm{C}$ in benzene ring. ${ }^{37}$ After heat treatment at $400{ }^{\circ} \mathrm{C}$, we still only observe a characteristic peak at $1599 \mathrm{~cm}^{-1}$ for the as-prepared $\mathrm{Fe}-\mathrm{C}_{x}$. When the treatment temperature was increased to $450{ }^{\circ} \mathrm{C}$ and more, two characteristic peaks at about $1333 \mathrm{~cm}^{-1}$ and $1590 \mathrm{~cm}^{-1}$ are attributed to the $\mathrm{D}$ band $\left(\mathrm{sp}^{3}-\mathrm{C}\right)$ and $\mathrm{G}$ band $\left(\mathrm{sp}^{2}-\mathrm{C}\right)$ of carbon, respectively, in addition, the intensity ratio of $\mathrm{D}$ band and $\mathrm{G}$ band $\left(I_{\mathrm{D}} / I_{\mathrm{G}}\right)$ increase with the increase of temperature. It indicates that the $\mathrm{sp}^{2}-\mathrm{C}$ in benzene ring could be decomposed at the temperature up to $450{ }^{\circ} \mathrm{C}$, and the organic ligands of PTA in Fe-MOF were gradually converted to amorphous carbon with the increase of temperature to $600^{\circ} \mathrm{C}$, which are consistent with the XRD results. These amorphous carbon is favour of the dispersion of iron oxides nanoparticles.

SEM image, shown in Fig. 3a, reveals that the Fe-MOF crystals are spindle-like shape with a nonuniform size and smooth surface. After treatment of the Fe-MOF crystals at $400^{\circ} \mathrm{C}$, we can observe that the spindle-like Fe-MOF crystals were transformed into homogeneous $\mathrm{Fe}-\mathrm{C}_{400}$ particles that are gathered together with single morphology and rough surface (Fig. 3b). When the temperature was increased to $500{ }^{\circ} \mathrm{C}$, it can be seen some graphene-like carbon sheets (Fig. 3c) from the pyrolysis of organic ligands. Moreover, lots of inorganic particles can be observed around these carbon sheets for $\mathrm{Fe}-\mathrm{C}_{500}$. After the temperature was further increased to $600{ }^{\circ} \mathrm{C}$, the as-prepared Fe- $\mathrm{C}_{600}$ (Fig. 3d) exhibit more carbon sheets than that of $\mathrm{Fe}-$ $\mathrm{C}_{500}$, and many octahedral nanocrystals were formed on the surface of carbon sheets. SEM analyses reveal that different 


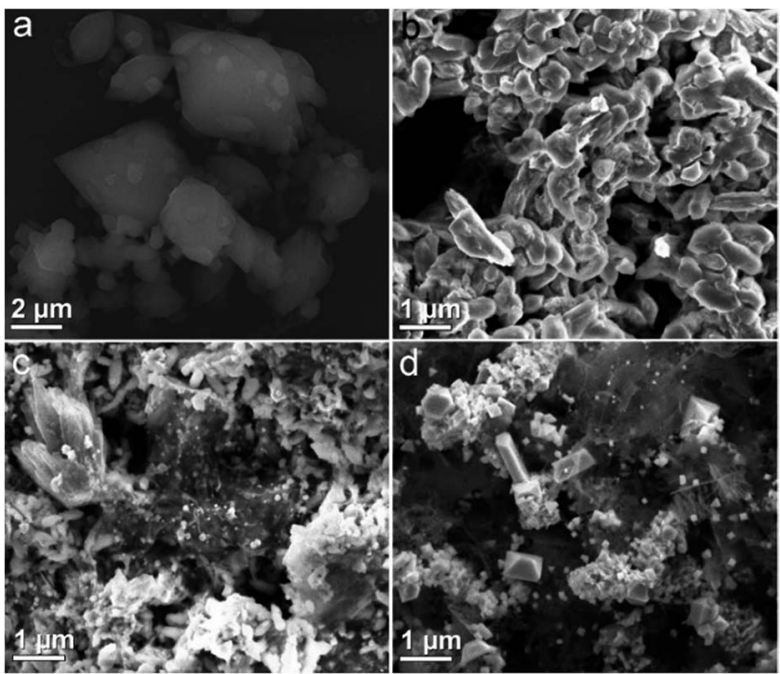

Fig. 3 SEM images of the (a) Fe-MOF, (b) Fe- $\mathrm{C}_{400}$, (c) $\mathrm{Fe}-\mathrm{C}_{500}$, and (d) $\mathrm{Fe}-\mathrm{C}_{600}$

annealing temperatures have a noticeable effect on the morphology of the as-synthesized products.

To study the porosity of all samples, $\mathrm{N}_{2}$ adsorption-desorption isotherms were measured, as depicted in Fig. 4. All of the isotherms present typical type IV profiles and H3 hysteresis loop on the basis of IUPAC classical-cation, indicating the similar pore structures of $\mathrm{Fe}^{-} \mathrm{C}_{x}$ and the predominance of the mesopore. ${ }^{38}$ The $\mathrm{H} 3$ hysteresis are typically given by aggregates of plate-shaped particles or adsorbents containing slit-shaped pores, ${ }^{39,40}$ implying the presence of carbon sheets in asprepared $\mathrm{Fe}-\mathrm{C}_{x}$ samples. Furthermore, the parameters of the porous structure and textural properties are listed in Table S1. $\dagger$ The BET specific surface area of $\mathrm{Fe}-\mathrm{C}_{400}, \mathrm{Fe}-\mathrm{C}_{450}, \mathrm{Fe}-\mathrm{C}_{500}$, $\mathrm{Fe}-\mathrm{C}_{550}, \mathrm{Fe}-\mathrm{C}_{600}$ are 49.1094, 42.9603, 86.6838, 171.2443 and $88.9648 \mathrm{~m}^{2} \mathrm{~g}^{-1}$ respectively. Besides, the average pore size of these materials is range from 8.3 to $11.8 \mathrm{~nm}$.

Fig. $4 \mathrm{~b}$ shows the zeta-potential diagrams of $\mathrm{Fe}-\mathrm{C}_{x}$. The point of zero charge $\left(\mathrm{pH}_{\mathrm{pzc}}\right)$ of various $\mathrm{Fe}-\mathrm{C}_{x}(x=400,450,500,550$, $600{ }^{\circ} \mathrm{C}$ ) was 3.7, 5.9, 4.9, 5.3 and 6.7 , respectively. As we known, when $\mathrm{pH}>\mathrm{pH}_{\mathrm{pzc}}$, the surface charge of the materials is negative, and will be positive at $\mathrm{pH}<\mathrm{pH}_{\mathrm{pzc}}$. Therefore, the surface charges of $\mathrm{Fe}-\mathrm{C}_{400}, \mathrm{Fe}-\mathrm{C}_{450}, \mathrm{Fe}-\mathrm{C}_{500}, \mathrm{Fe}-\mathrm{C}_{550}$ were negative in Fenton-like reaction system at circumneutral $\mathrm{pH}=6.21$, in contrast, the $\mathrm{Fe}-\mathrm{C}_{600}$ was positive.
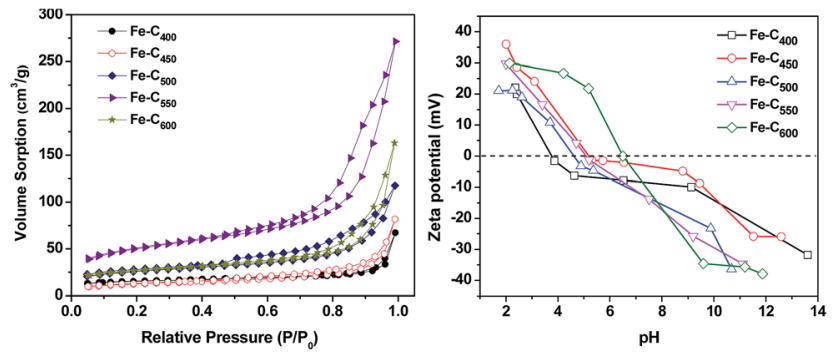

Fig. 4 (a) Nitrogen adsorption isotherms and (b) zeta-potential curves of $\mathrm{Fe}-\mathrm{C}_{x}$.
Fig. 5 show the XPS spectra in the surface of $\mathrm{Fe}-\mathrm{C}_{x}$ composites. Full-view (Fig. 5a) of XPS spectra indicates that composites have iron, carbon, oxygen, chlorine, and nitrogen elements, which contained in the pristine $\mathrm{Fe}-\mathrm{MOF}\left(\mathrm{Fe}_{3}(\mathrm{O}) \mathrm{Cl}\right.$ $\left[\mathrm{C}_{6} \mathrm{H}_{4}\left(\mathrm{CO}_{2}\right)_{2}\right]_{3}\left(\mathrm{C}_{3} \mathrm{H}_{7} \mathrm{NO}\right)$ ) (Table $\left.\mathrm{S} 2 \uparrow\right)$. Besides, the gradually decreasing of mass ratios of chlorine and oxygen in the asprepared $\mathrm{Fe}-\mathrm{C}_{x}$ composites indicates that the chlorine and oxygen escaped during the production of iron oxides/carbon. Fig. $5 \mathrm{~b}$ shows the XPS spectra of Fe $2 \mathrm{p}$ for Fe-MOF and $\mathrm{Fe}-\mathrm{C}_{x}$ composites. For the pristine Fe-MOF, we can see two main peaks at 711.5 and $725 \mathrm{eV}$ and a satellite peak at $718.5 \mathrm{eV}$, which matches well with the MOF of MIL-Fe ${ }^{41,42}$ The spectra of Fe $2 \mathrm{p}$ for $\mathrm{Fe}-\mathrm{C}_{400}$ and $\mathrm{Fe}-\mathrm{C}_{450}$ show three peaks at 711.5, 715.8 and $724.6 \mathrm{eV}$, indicating that the chemical environment of Fe(III) had changed but possibly still bonded with benzene rings in asprepared $\mathrm{Fe}-\mathrm{C}_{400}$ and $\mathrm{Fe}-\mathrm{C}_{450}$. The spectra of $\mathrm{Fe} 2 \mathrm{p}$ for $\mathrm{Fe}-$ $\mathrm{C}_{500}$ and $\mathrm{Fe}-\mathrm{C}_{550}$ show two main peaks at 711.6 and $724.8 \mathrm{eV}$, and a satellite peak of $718.5 \mathrm{eV}$, which are in good agreement with the reported values for $\mathrm{Fe}_{2} \mathrm{O}_{3} \cdot{ }^{43}$ It indicates that the most of Fe-MOFs had been converted into iron oxides at the pyrolysis temperature of 500 and $550{ }^{\circ} \mathrm{C}$. For $\mathrm{Fe}-\mathrm{C}_{600}$, the peak positions of $\mathrm{Fe} 2 \mathrm{p}_{3 / 2}$ and $\mathrm{Fe} 2 \mathrm{p}_{1 / 2}$ are, respectively, 711.1 and $724.6 \mathrm{eV}$, and no obviously satellite peak presents, which is well consistent with the results of reported $\mathrm{Fe}_{3} \mathrm{O}_{4}{ }^{43,44}$ In addition, a peak at $711.1 \mathrm{eV}$ for $\mathrm{Fe}-\mathrm{C}_{550}$ indicates that there have $\mathrm{Fe}_{3} \mathrm{O}_{4}$ particles. The $\mathrm{C} 1 \mathrm{~s}$ spectra of Fe-MOF and $\mathrm{Fe}-\mathrm{C}_{x}$ are presented in Fig. 2c. As we can see that the main peak at $284.8 \mathrm{eV}$ for Fe-MOF gradually shifted to $285 \mathrm{eV}$ for $\mathrm{Fe}-\mathrm{C}_{600}$, which confirms the loss of $\mathrm{COO}$ groups and pyrolysis of benzene ring. The $\mathrm{C} 1 \mathrm{~s}$ spectra of $\mathrm{Fe}-\mathrm{MOF}$ and $\mathrm{Fe}^{-} \mathrm{C}_{x}$ can be deconvoluted to three peaks at about 285, 286, and $289.5 \mathrm{eV}$ (Fig. S1†), corresponding to $\mathrm{C}-\mathrm{C}, \mathrm{C}-\mathrm{O}$, and $\mathrm{O}-\mathrm{C}=\mathrm{O}$ groups, respectively. With the increase of temperature, the peak at $289.5 \mathrm{eV}$ gradually disappears (Fig. 5c), indicating that the carbonyl groups were decomposed to $\mathrm{CO}$ or $\mathrm{CO}_{2}$ gas gradually. Fig. $5 \mathrm{~d}$ shows the $\mathrm{O} 1 \mathrm{~s}$
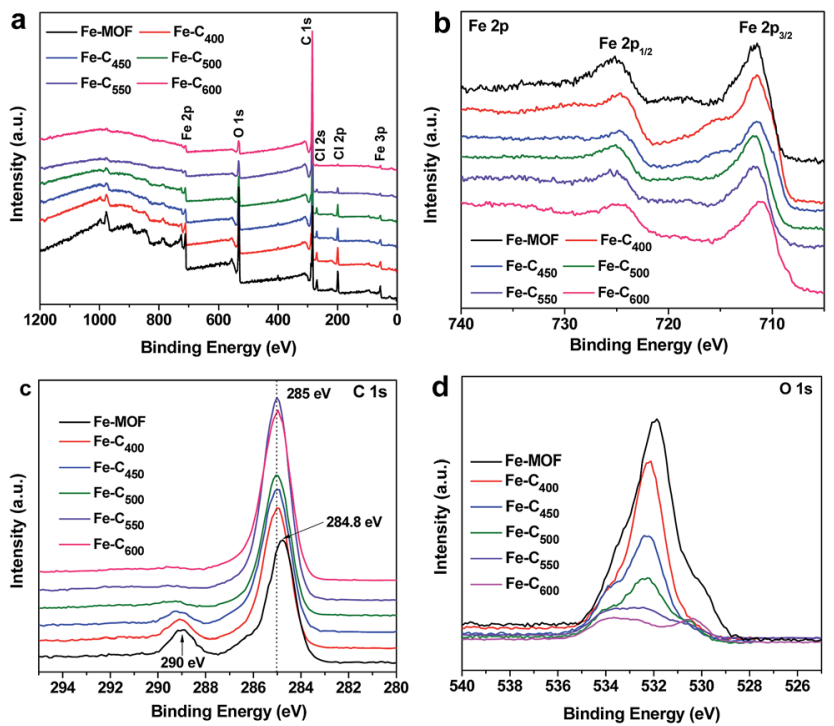

Fig. 5 XPS spectra of (a) full-view, (b) Fe $2 p$ and (c) $C 1$ s and (d) $O 1$ s for $\mathrm{Fe}-\mathrm{MOF}$ and $\mathrm{Fe}-\mathrm{C}_{x}$. 
spectra of Fe-MOF and $\mathrm{Fe}-\mathrm{C}_{x}$ composites. Obviously, the content of oxygen-containing groups was reduced with the increase of temperature. As shown in Fig. S2a, $\dagger$ the $\mathrm{O} 1 \mathrm{~s}$ spectra of Fe-MOF can be fitted to three peaks at 530.1, 531.9 and $533.5 \mathrm{eV}$, corresponding to $\mathrm{Fe}-\mathrm{O}, \mathrm{C}-\mathrm{O}$, and $\mathrm{C}=\mathrm{O}$ groups. After heat treatment, all the three peaks shifted to about 530.8, 532.5 and $533.9 \mathrm{eV}$ (Fig. S2 $\dagger$ ), indicating the change of chemical environment of oxygen in Fe-MOF and $\mathrm{Fe}-\mathrm{C}_{x}$. According to the above characterization, the speculated main components of Fe- $\mathrm{C}_{x}$ at different pyrolysis temperature are listed in Table S3. $\dagger$

\subsection{Heterogeneous Fenton-like degradation of 4-NP by Fe- $\mathrm{C}_{x}$}

3.2.1 Effect of pyrolysis temperature. Fig. 6 presents the catalytic efficiencies of pristine $\mathrm{Fe}-\mathrm{MOF}$ and various $\mathrm{Fe}-\mathrm{C}_{x}$ $\left(0.08 \mathrm{~g} \mathrm{~L}^{-1}\right)$ for the heterogeneous Fenton-like degradation of 4$\mathrm{NP}(250 \mathrm{~mL}, 0.36 \mathrm{mM})$ at unadjusted circumstance $\mathrm{pH} 6.21$ and $18{ }^{\circ} \mathrm{C}$ with $7.8 \mathrm{mM}$ of $\mathrm{H}_{2} \mathrm{O}_{2}$ dosage. As it shown above, $48.1 \mathrm{wt} \%$ 4 -NP can be decomposed by pristine Fe-MOF in above catalytic system. Meanwhile, as high as 87.4, 88.0, 89.0, and 83.8 wt\% removal efficiency of 4-NP could be achieved within 75 min by using of $\mathrm{Fe}-\mathrm{C}_{400}, \mathrm{Fe}-\mathrm{C}_{450}, \mathrm{Fe}-\mathrm{C}_{500}, \mathrm{Fe}-\mathrm{C}_{550}$, respectively. However, $\mathrm{Fe}-\mathrm{C}_{600}$ exhibited weak catalytic activity for the degradation of $4-\mathrm{NP}$, less than 8 and $4 \mathrm{wt} \%$ of $4-\mathrm{NP}$ was degraded, respectively. It indicated that the annealing temperature could significantly affect the Fenton-like catalytic activity of as-prepared $\mathrm{Fe}-\mathrm{C}_{x}$, the multicomponent $\mathrm{Fe}-\mathrm{C}_{500}$ showed the best catalytic activity for the degradation of 4-NP. Furthermore, at the initial of the reaction (30 $\mathrm{min}$ ), we can observe that the degradation rate of $4-\mathrm{NP}$ on $\mathrm{Fe}-\mathrm{C}_{450}$ was faster than that of $\mathrm{Fe}-$ $\mathrm{C}_{500}$ sample, which indicated that the formation rates of $\mathrm{Fe}^{2+}$ for the sample of $\mathrm{Fe}-\mathrm{C}_{450}$ was faster than that of $\mathrm{Fe}-\mathrm{C}_{500}$ at the beginning of the Fenton-like reaction (Fig. 6).

3.2.2 Effects of catalyst loading. To further study the catalytic activity of $\mathrm{Fe}-\mathrm{C}_{500}$, the influence factors, such as catalyst loading, $\mathrm{H}_{2} \mathrm{O}_{2}$ dosage, reaction temperature and initial $\mathrm{pH}$ of solution, on the degradation efficiency of $4-\mathrm{NP}$ by $\mathrm{Fe}-\mathrm{C}_{500}$ were analysed in detail, and shown in Fig. 7. Fig. 7a shows the

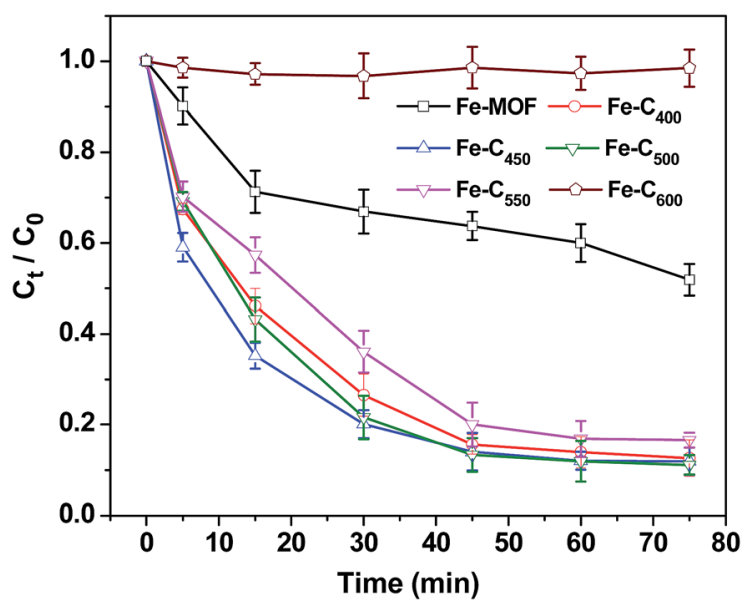

Fig. 6 Degradation of 4-NP by Fe-MOF and Fe-C . [4-NP] $=$ $0.36 \mathrm{mM}$, catalyst $=0.08 \mathrm{~g} \mathrm{~L}^{-1},\left[\mathrm{H}_{2} \mathrm{O}_{2}\right]=7.8 \mathrm{mM}, T=18^{\circ} \mathrm{C}, \mathrm{pH} 6.21$.
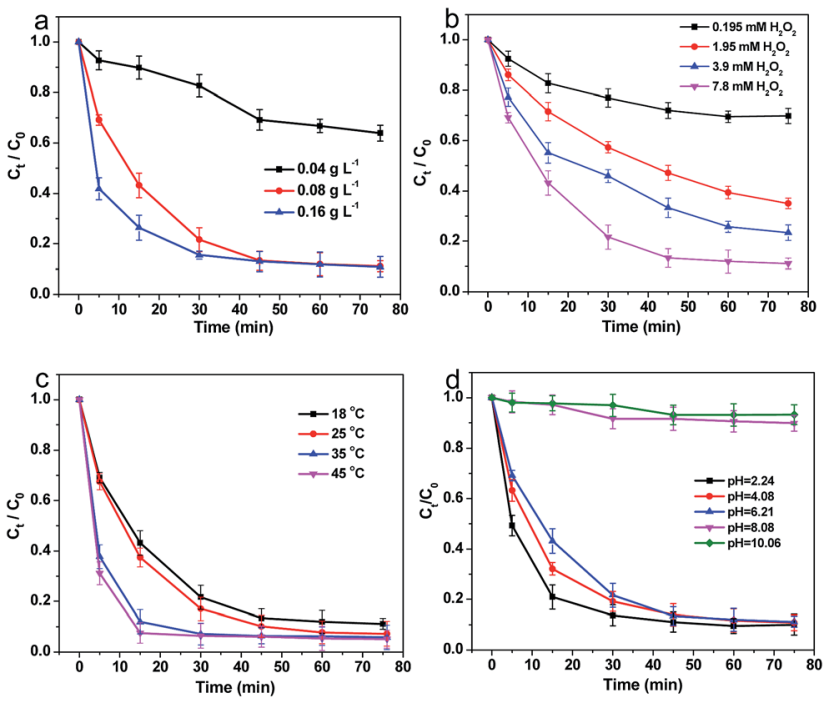

Fig. 7 Effects of reaction conditions on the degradation 4-NP by Fe$\mathrm{C}_{500}$. (a) Catalyst loading, (b) $\mathrm{H}_{2} \mathrm{O}_{2}$ dosage, (c) reaction temperature, and (d) initial $\mathrm{pH}$.

degradation of 4-NP using various catalyst loading (0.04, 0.08 and $0.16 \mathrm{~g} \mathrm{~L}^{-1}$ ) under the aids of $7.8 \mathrm{mM}^{\circ} \mathrm{H}_{2} \mathrm{O}_{2}$ at $18{ }^{\circ} \mathrm{C}$. When the content of $\mathrm{Fe}-\mathrm{C}_{500}$ was $0.04 \mathrm{~g} \mathrm{~L}^{-1}$, the value of $C_{t} / C_{0}$ was high up to be 0.64 , while the $C_{t} / C_{0}$ can be approached to 0.11 in 75 min with the loading of $\mathrm{Fe}-\mathrm{C}_{500}$ increasing to $0.08 \mathrm{~g} \mathrm{~L}^{-1}$. In addition, further increasing the concentration of catalysts, the $C_{t} / C_{0}$ still stayed near 0.11 , but the degradation rate of 4 -NP was distinctly accelerated. Therefore, the increase of the catalysts loading was favourable to the degradation of 4-NP in water. To quantitatively evaluate the effect of $\mathrm{Fe}-\mathrm{C}_{500}$ loading for the catalytic performance, the pseudo-first order equation (eqn (1)) was used to fit the degradation of $4-\mathrm{NP}$ in water.

$$
C_{t}=C_{0} \exp (-k t)
$$

where $k$ is the apparent rate constant of the 4-NP degradation. The $k$ values were calculated and listed in Table 1 . When the loading of catalyst rose from 0.04 to $0.16 \mathrm{~g} \mathrm{~L}^{-1}$, the $k$ value increased from 0.35 to $3.37 \mathrm{~h}^{-1}$.

3.2.3 Effects of $\mathrm{H}_{2} \mathrm{O}_{2}$ dosage. Fig. 7b shows the effects of $\mathrm{H}_{2} \mathrm{O}_{2}$ dosage on the removal of 4 -NP by $0.08 \mathrm{~g} \mathrm{~L}^{-1}$ catalysts at

Table 1 Pseudo-first order rate constants for 4-NP removal under different conditions using $\mathrm{Fe}-\mathrm{C}_{500}$ catalysts

\begin{tabular}{lllcl}
\hline $\mathrm{Fe}-\mathrm{C}_{500}\left(\mathrm{mg} \mathrm{L}^{-1}\right)$ & $\mathrm{H}_{2} \mathrm{O}_{2}(\mathrm{mM})$ & $T\left({ }^{\circ} \mathrm{C}\right)$ & $k\left(\mathrm{~h}^{-1}\right)$ & $R$ \\
\hline 0.04 & 7.8 & 18 & 0.35 & 0.90948 \\
0.08 & 7.8 & 18 & 2.98 & 0.98997 \\
0.16 & 7.8 & 18 & 3.37 & 0.81872 \\
0.08 & 7.8 & 25 & 3.48 & 0.99255 \\
0.08 & 7.8 & 35 & 8.29 & 0.95969 \\
0.08 & 7.8 & 45 & 10.1 & 0.96416 \\
0.08 & 0.195 & 18 & 0.35 & 0.90013 \\
0.08 & 1.95 & 18 & 0.83 & 0.97503 \\
0.08 & 3.9 & 18 & 1.28 & 0.96035
\end{tabular}


$18{ }^{\circ} \mathrm{C}$. Obviously, the higher dosage of $\mathrm{H}_{2} \mathrm{O}_{2}$ could result in the higher degradation efficiency as $C_{t} / C_{0}$ almost reached 0.11 in 60 min using $7.8 \mathrm{mM}$ of $\mathrm{H}_{2} \mathrm{O}_{2}$. When the concentration of $\mathrm{H}_{2} \mathrm{O}_{2}$ was increased from $0.195 \mathrm{mM}$ to $7.8 \mathrm{mM}, k$ rose from 0.35 to $2.99 \mathrm{~h}^{-1}$. Overall, $\mathrm{H}_{2} \mathrm{O}_{2}$ dosage played an important role in degradation of 4-NP, and a sufficient $\mathrm{H}_{2} \mathrm{O}_{2}$ dosage was needful for effectively removal of pollutants.

3.2.4 Effects of reaction temperature. The effect of reaction temperature was studied by changing the temperature of 4-NP solution from $18{ }^{\circ} \mathrm{C}$ to $45{ }^{\circ} \mathrm{C}$. When the temperature was increased from $18{ }^{\circ} \mathrm{C}$ to $35^{\circ} \mathrm{C}$, the kinetics became much faster from $k$ of $3.37 \mathrm{~h}^{-1}$ to $k$ of $8.29 \mathrm{~h}^{-1}$ (Fig. 7c), which demonstrated the higher temperature could enhance the degradation of 4-NP. Similarly, the $k$ increased to $10.1 \mathrm{~h}^{-1}$ with the temperature up to $45{ }^{\circ} \mathrm{C}$.

As the $k$ value increased at higher temperatures, the Arrhenius equation was adopted to calculate the activation energy as the following equation:

$$
\ln k=\ln k_{0}-\frac{E_{\mathrm{a}}}{R} \frac{1}{T}
$$

where $E_{\mathrm{a}}$ represents the activation energy $\left(\mathrm{kJ} \mathrm{mol}^{-1}\right), k_{0}$ means the temperature-independent factor $\left(\mathrm{g} \mathrm{mg}^{-1} \mathrm{~min}^{-1}\right) ; T$ denotes the solution temperature in Kelvin (K) and $R$ is the universal gas constant. The Arrhenius linear plot of the degradation of 4-NP by $\mathrm{Fe}-\mathrm{C}_{500}\left(0.08 \mathrm{~g} \mathrm{~L}^{-1}\right)$ with the addition of $7.8 \mathrm{mM} \mathrm{H}_{2} \mathrm{O}_{2}$ at four different temperature is presented in Fig. S3. $\dagger$ The $E_{\mathrm{a}}$ of the reaction on the $\mathrm{Fe}-\mathrm{C}_{500}$ surface evaluated by plotting $\ln k$ against $1 / T$ and was $38.5 \mathrm{~kJ} \mathrm{~mol}^{-1}$. This value is higher than the activation energy of the diffusion-controlled reactions, which usually ranges in $10-13 \mathrm{~kJ} \mathrm{~mol}^{-1} \cdot{ }^{45}$ It indicates that the Fenton reaction rate is dominated by the rate of intrinsic chemical reactions on the $\mathrm{Fe}-\mathrm{C}_{500}$ surface rather than the rate of mass transfer. The value of $E_{\mathrm{a}}$ in our study is between 20.7 and $56.1 \mathrm{~kJ} \mathrm{~mol}^{-1}$ of the activation energy of Fenton reactions using different heterogeneous catalysts from literature data, ${ }^{\mathbf{4 6}}$ indicating that $\mathrm{Fe}-\mathrm{C}_{500}$ composite showed a high catalytic activity in heterogeneous Fenton reaction of 4-NP.

3.2.5 Effects of initial pH. The effect of pH (Fig. 7d) was also investigated by changing the initial $\mathrm{pH}$ of 4-NP solvents to 2.24, 4.08, unadjusted 6.21, 8.08 and 10.06, corresponding to acidic, circumneutral and basic conditions, respectively. The degradation rate of 4-NP was faster at initial $\mathrm{pH}=2.24$ and 4.08, which suggested that the acid condition is beneficial to the catalytic degradation. In addition, the degradation of 4-NP was efficient without adjusting the initial $\mathrm{pH}$ (6.21) of reaction solution. When the initial $\mathrm{pH}$ of solution was adjusted to 8.08 and 10.06 , the 4-NP removal by oxidation scarcely occurred.

\subsection{Recyclability of $\mathrm{Fe}-\mathrm{C}_{500}$}

The potential to reuse $\mathrm{Fe}-\mathrm{C}_{500}$ for degradation of $4-\mathrm{NP}$ was tested and shown in Fig. 8a. At the 1st cycle, $89.0 \mathrm{wt} \%$ of $4-\mathrm{NP}$ can be degraded, and reduced to $61.1 \mathrm{wt} \%$ at the 2 nd cycle. It is mainly attributed to that part of iron in $\mathrm{Fe}-\mathrm{C}_{500}$ was dissolved during the 1st cycle. After two cycles, the Fenton-like catalytic activity of $\mathrm{Fe}-\mathrm{C}_{500}$ was stable, 54.2 and $52.4 \mathrm{wt} \% 4-\mathrm{NP}$ was

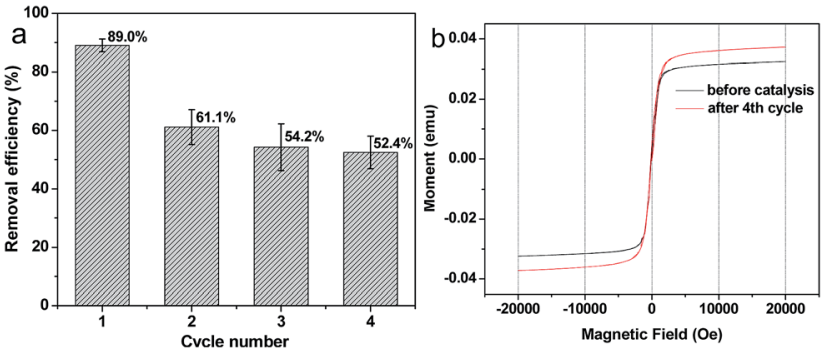

Fig. 8 (a) Reusable degradation activity for $\mathrm{Fe}-\mathrm{C}_{500}$ up to 4 cycles and (b) hysteresis loop of $\mathrm{Fe}-\mathrm{C}_{500}$ before catalysis and after 4 cycles.

removed at the $3 \mathrm{rd}$ and 4 th cycle, respectively. Fig. $8 \mathrm{~b}$ shows the hysteresis loop of $\mathrm{Fe}-\mathrm{C}_{500}$ before catalysis and after 4 cycles. A typical "S"-like shape of the hysteresis loop was observed, indicating the paramagnetic properties of the samples, and the magnetic $\mathrm{Fe}-\mathrm{C}_{500}$ can be easily recovered by using a magnet after 4 cycles (Fig. S4†). In addition, the saturation magnetization of $\mathrm{Fe}-\mathrm{C}_{500}$ after 4 cycles is higher than that of the catalyst before the catalytic reaction, which imply that the loss of iron from $\mathrm{Fe}-\mathrm{C}_{500}$ mainly come from the iron-organic ligands but not the iron oxides.

\section{Conclusions}

In summary, various $\mathrm{Fe}-\mathrm{C}_{x}$ nanocomposites could be prepared using Fe-MOF as precursors under $\mathrm{N}_{2}$ protection. The pyrolysis temperature could affect the component, structure and morphology of as-prepared $\mathrm{Fe}-\mathrm{C}_{x}$ nanocomposites. Furthermore, the reaction condition, such as the catalyst loading, $\mathrm{H}_{2} \mathrm{O}_{2}$ dosage, reaction temperature, and initial $\mathrm{pH}$ could significantly affect the catalytic degradation of 4-NP on the surface of $\mathrm{Fe}-\mathrm{C}_{x}$ nanocomposites. The oxidation degradation of 4-NP indicated that the $\mathrm{Fe}-\mathrm{C}_{500}$ showed the best heterogeneous Fenton-like catalytic activity with $89.0 \mathrm{wt} \%$ removal efficiency of $250 \mathrm{~mL}$ $0.36 \mathrm{mM}$ of 4 -NP within $75 \mathrm{~min}$ by using $0.08 \mathrm{~g} \mathrm{~L}^{-1}$ of catalyst loading and $7.8 \mathrm{mM} \mathrm{H}_{2} \mathrm{O}_{2}$ at $18{ }^{\circ} \mathrm{C}$. Furthermore, the magnetic $\mathrm{Fe}-\mathrm{C}_{500}$ can be easily recycled by using a magnet. The impressive results showed that the preparation of magnetic carbon nanocomposites derived from Fe-MOFs at suitable pyrolysis temperature is an effective route to fabricate high performance Fenton-like catalyst for degradation of organic pollutants in aqueous solution.

\section{Conflicts of interest}

There are no conflicts to declare.

\section{Acknowledgements}

This work was supported by the National Natural Science Foundation of China (51402146), the National Science Foundation for Excellent Young Scholars (51422807), the Natural Science Foundation (20171BAB206046) of Jiangxi Province, and the Science and Technology Planning Project (20151BBG70019) of Jiangxi Province. 


\section{Notes and references}

1 A. Myridakis, G. Chalkiadaki, M. Fotou, M. Kogevinas, L. Chatzi and E. G. Stephanou, Environ. Sci. Technol., 2016, 50, 932-941.

2 Y. Z. Gong, K. Baylis, R. Kozak and G. Bull, Agr. Econ., 2016, 47, 411-421.

3 F. Zietzschmann, C. Stuetzer and M. Jekel, Water Res., 2016, 92, 180-187.

4 S. Y. Jia, Z. Yang, W. B. Yang, T. T. Zhang, S. P. Zhang, X. Z. Yang, Y. Y. Dong, J. Q. Wu and Y. P. Wang, Chem. Eng. J., 2016, 283, 495-503.

5 J. Li, R. Kang, X. Tang, H. She, Y. Yang and F. Zha, Nanoscale, 2016, 8, 7638-7645.

6 T. T. More, J. S. Yadav, S. Yan, R. D. Tyagi and R. Y. Surampalli, J. Environ. Manage., 2014, 144, 1-25.

7 O. G. Apul and T. Karanfil, Water Res., 2015, 68, 34-55.

8 S. Hokkanen, A. Bhatnagar and M. Sillanpaa, Water Res., 2016, 91, 156-173.

9 D. Chen, W. Shen, S. Wu, C. Chen, X. Luo and L. Guo, Nanoscale, 2016, 8, 172-179.

10 S. Giannakis, F. A. G. Vives, D. Grandjean, A. Magnet, L. F. De Alencastro and C. Pulgarin, Water Res., 2015, 84, 295-306.

11 S. G. Ardo, S. Nelieu, G. Ona-Nguema, G. Delarue, J. Brest, E. Pironin and G. Morin, Environ. Sci. Technol., 2015, 49, 4506-4514.

12 X. Li, Z. Wang, B. Zhang, A. I. Rykov, M. A. Ahmed and J. Wang, Appl. Catal., B, 2016, 181, 788-799.

13 S. H. Yoo, D. Jang, H.-I. Joh and S. Lee, J. Mater. Chem. A, 2017, 5, 748-755.

14 Y. Yao, H. Chen, J. Qin, G. Wu, C. Lian, J. Zhang and S. Wang, Water Res., 2016, 101, 281-291.

15 M. Munoz, Z. M. de Pedro, J. A. Casas and J. J. Rodriguez, Appl. Catal., B, 2015, 176-177, 249-265.

16 H. Lv, H. Zhao, T. Cao, L. Qian, Y. Wang and G. Zhao, J. Mol. Catal. A: Chem., 2015, 400, 81-89.

17 K.-Y. A. Lin and F.-K. Hsu, RSC Adv., 2015, 5, 50790-50800.

18 X.-J. Yang, X.-m. Xu, J. Xu and Y.-F. Han, J. Am. Chem. Soc., 2013, 135, 16058-16061.

19 H. Chen, Z. L. Zhang, Z. L. Yang, Q. Yang, B. Li and Z. Y. Bai, Chem. Eng. J., 2015, 273, 481-489.

20 J. H. Deng, J. Y. Jiang, Y. Y. Zhang, X. P. Lin, C. M. Du and Y. Xiong, Appl. Catal., B, 2008, 84, 468-473.

21 I. S. X. Pinto, P. Pacheco, J. V. Coelho, E. Lorencon, J. D. Ardisson, J. D. Fabris, P. P. de Souza, K. W. H. Krambrock, L. C. A. Oliveira and M. C. Pereira, Appl. Catal., B, 2012, 119, 175-182.

22 L. Xu and J. Wang, Appl. Catal., B, 2012, 123-124, 117-126.
23 M. J. Jin, M. C. Long, H. R. Su, Y. Pan, Q. Z. Zhang, J. Wang, B. X. Zhou and Y. W. Zhang, Environ. Sci. Pollut. Res., 2017, 24, 1926-1937.

24 Y. Pan, M. Zhou, X. Li, L. Xu, Z. Tang and M. Liu, Sep. Purif. Technol., 2016, 169, 83-92.

25 L. Yu, X. Yang, Y. Ye and D. Wang, RSC Adv., 2015, 5, 4605946066.

26 V. Cleveland, J.-P. Bingham and E. Kan, Sep. Purif. Technol., 2014, 133, 388-395.

27 M. Goncalves, M. C. Guerreiro, L. C. de Oliveira and C. S. de Castro, J. Environ. Manage., 2013, 127, 206-211.

28 M. R. Carrasco-Diaz, E. Castillejos-Lopez, A. Cerpa-Naranjo and M. L. Rojas-Cervantes, Microporous Mesoporous Mater., 2017, 237, 282-293.

29 Y. Yao, H. Chen, C. Lian, F. Wei, D. Zhang, G. Wu, B. Chen and S. Wang, J. Hazard. Mater., 2016, 314, 129-139.

30 C. Zhang, F. Ye, S. Shen, Y. Xiong, L. Su and S. Zhao, RSC $A d v ., 2015$, 5, 8228.

31 X. Li, A. I. Rykov, B. Zhang, Y. Zhang and J. Wang, Catal. Sci. Technol., 2016, 6, 7486-7494.

32 K. A. Lin and B. J. Chen, Chemosphere, 2017, 166, 146-156.

33 X. Cao, B. Zheng, X. Rui, W. Shi, Q. Yan and H. Zhang, Angew. Chem., Int. Ed., 2013, DOI: 10.1002/anie.201308013.

34 L. Wang, Y. Zhang, X. Li, Y. Xie, J. He, J. Yu and Y. Song, Sci. Rep., 2015, 5, 14341.

35 X. Cai, J. Lin and M. Pang, Cryst. Growth Des., 2016, 16, 35653568.

36 T. Yamada, K. Shiraishi, H. Kitagawa and N. Kimizuka, Chem. Commun., 2017, 53, 8215-8218.

37 G.-T. Vuong, M.-H. Pham and T.-O. Do, CrystEngComm, 2013, 15, 9694.

38 Y. Li, Q. Zhang, J. Zhang, L. Jin, X. Zhao and T. Xu, Sci. Rep., 2015, 5, 14155.

39 K. S. W. Sing and R. T. Williams, Adsorpt. Sci. Technol., 2004, 22, 773-782.

40 M. Díaz Ramos, G. I. Giraldo Gómez and N. Sanabria González, J. Mol. Catal. B: Enzym., 2014, 99, 79-84.

41 S.-H. Huo and X.-P. Yan, J. Mater. Chem., 2012, 22, 7449.

42 W. Cho, S. Park and M. Oh, Chem. Commun., 2011, 47, 41384140.

43 T. Yamashita and P. Hayes, Appl. Surf. Sci., 2008, 254, 24412449.

44 J. A. Cuenca, K. Bugler, S. Taylor, D. Morgan, P. Williams, J. Bauer and A. Porch, J. Phys.: Condens. Matter, 2016, 28, 106002.

45 S.-S. Lin and M. D. Gurol, Environ. Sci. Technol., 1998, 32, 1417-1423.

46 L. Xu and J. Wang, Environ. Sci. Technol., 2012, 46, 1014510153. 